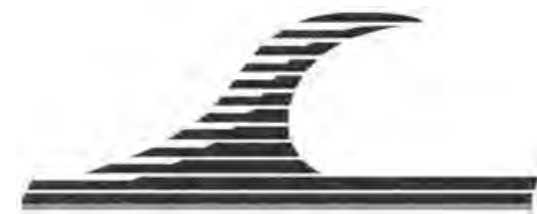

\title{
Handling of high resolution DTM to detect obstacles and map sea flooding. Examples on the French Mediterranean Coast
}

\author{
Céline TRMAL ${ }^{1}$, Frédéric PONS ${ }^{1}$
}

\author{
1. Cerema, Pôle d'Activités Les Milles, Avenue Albert Einstein, CS 70499 Aix-en- \\ Provence Cedex 3, France. \\ celine.trmal@cerema.fr ; frederic.pons@cerema.fr
}

\begin{abstract}
:
During the implementation of the EU Flood directive, high resolution (Lidar) digital terrain models (DTM) were produced massively on nearly all the French coast.

With those date, the methods used to map sea flooding on the Mediterranean coast were the simple superposition of a sea level on the natural terrain.

The methods currently implementing allow, comparing the previous results and the areas actually connected to the sea for a given level, to determine the protected area for this level.

The next step is to determine, where appropriate, the protection system. The algorithm developed for this purpose can locate it and determine its level of protection.
\end{abstract}

Translated version of a paper in French (DOI reference: http://dx.doi.org/10.5150/cmcm.2015.045), presented during the edition 3 of the Coastal and Maritime Mediterranean Conference,

(25-27 November 2015) in Ferrara, Italy. Received 04 September 2015, accepted 11 December 2015, available online 08 March 2016. 


\section{Introduction}

As part of the European Flood Directive (DI, DIRECTIVE 2007/60/CE - EP \& COUNCIL OF THE EU, 2007), high resolution (Lidar) digital terrain models (DTM) were produced massively on nearly all the French coast and particularly on the entire Mediterranean coast (from the Spanish border to the Italian border and on the Corsican coast).

In the same context, in 2012-13, sea flooding maps were performed for 4 events (frequent, medium, medium + climate change, extreme) using a method of superposition of the ad hoc sea level in the DTM. This simplified method was used to map sea flooding on very large linear of coast. However, this method has some limitations, including that of flooding far inland in flat areas, as long as the terrain elevation is below sea level (e.g. the Camargue) and also flooding low land with no connection to the sea.

In the same vein of mapping over large areas, we studied the possibility of improving this approach by trying to limit the extension of the flooding, to detect obstacles to flooding and determine protected areas.

These new concepts are implemented based on the Qgis software for the visualization of results and on the Grass software to perform calculations with a $\mathrm{R}$ interface for automation on large areas (TRMAL et al., 2015).

\section{Determination of potentially protected areas}

The geographic information system (GIS) mapping tools allow now, for a given sea level, extending the sea flooding in areas connected to the sea. In practice a given sea level is injected at sea and then the DTM pixels are analyzed from neighbor to neighbor to identify those lower to a given level and those which are also adjacent to a pixel already flooded. The r.lake Grass module was used.

This routine is implemented for a series of sea levels uniformly spaced.

The method of sea levels superposition on the DTM regardless of the connections is also implemented for these levels (Flood Directive method ID).

A potentially protected area is then defined as an area flooded by sea level/DTM superposition method and not flooded by the method using the connections.

Comparing the two results for each sea level gives potentially protected areas for the given level (see Figure 1).

For example an area can be protected a priori for a level of 2.5 metres NGF (flooded with the simple method) and not be for $3 \mathrm{~m} \mathrm{NGF}$ (flooded for the 2 methods), which means that it is protected by an embankment or natural terrain between 2.5 and $3 \mathrm{~m}$ NGF high (step of sea levels: $0.5 \mathrm{~m}$ ). 


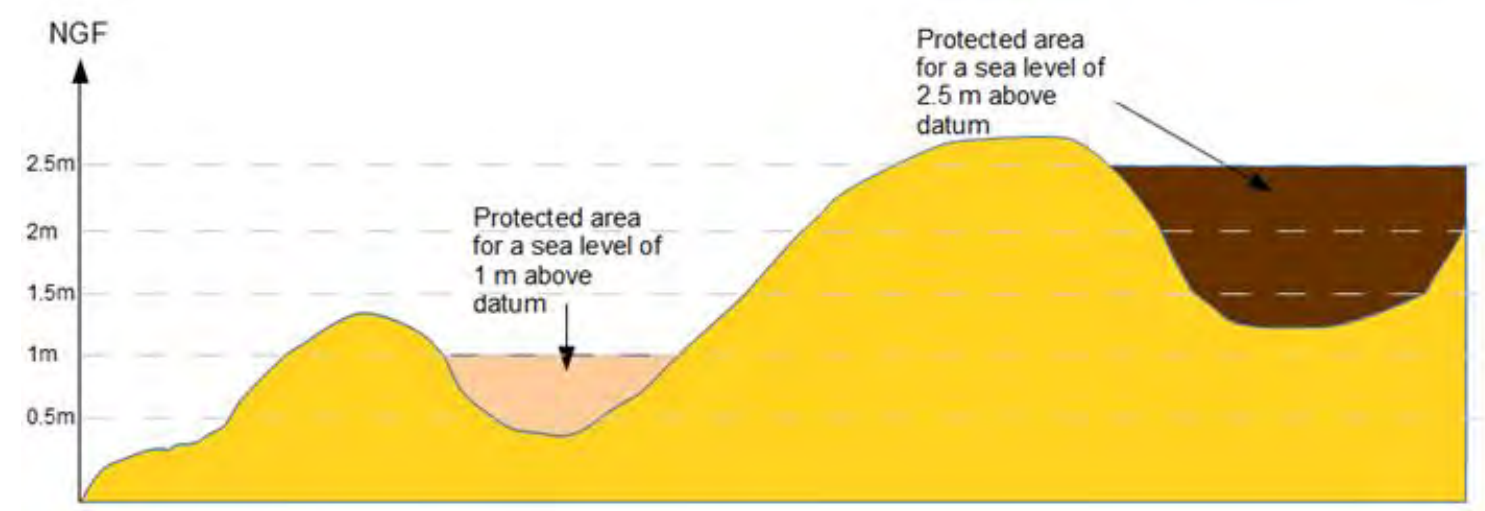

Figure 1. Sketch of the determination of potentially protected areas.

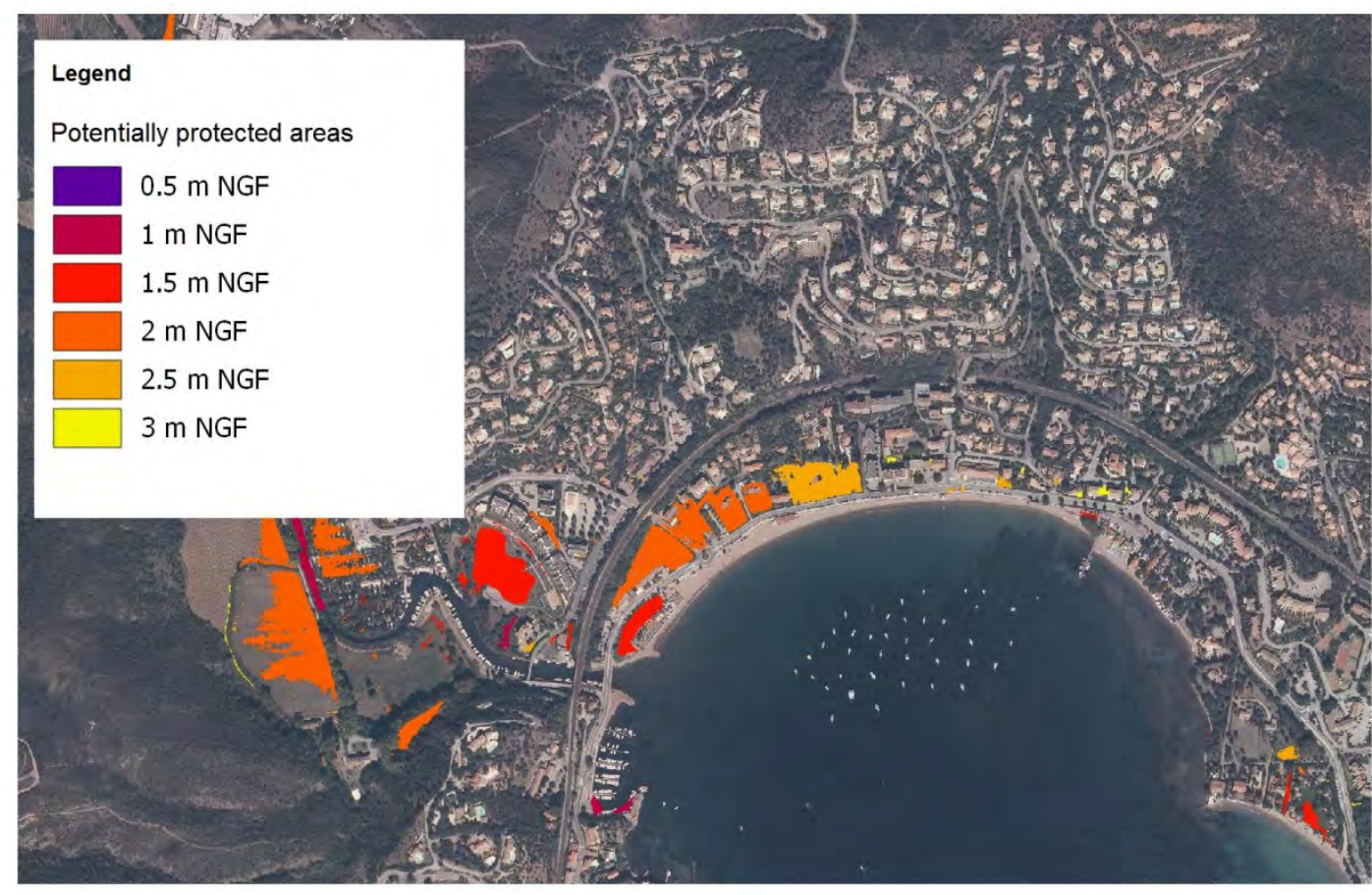

Figure 2. Example of results for potentially protected area (Baie d'Agay).

Some limitations were identified during the implementation.

The first one is intrinsic to the GIS method. A connection by a single pixel (1 metre wide in the case of the DTM used), even in diagonal, is sufficient to pass an infinite volume of water. But in reality a gap of one metre is not going to pass up such a volume. A parade is to harden the DTM by modifying the initial DTM by a maximum neighborhood window of a given size. For example, a neighborhood window size of 25 pixels (i.e. $25 \mathrm{~m}$ ) is used to pass the water only if the gap has a width of at least $25 \mathrm{~m}$. 
The second one is related to the DTM quality. The DTM, we used, were often isued from topographic Lidar and therefore they do not well represent the bathymetry of the streams. It is then necessary to dig rivers flowing into the sea so that seawater can go up the river in case of high sea levels.

\section{Detection of obstacles to sea flooding}

One of the key points for either high-output mapping or numerical hydraulic modeling is the knowledge of the location of dikes, embankments or sand dunes, especially to complete previous work and identify the systems that protect those areas.

As part of our various works, several methods of embankment detection were tested such as the determination of slope failures and analysis of field curvatures. The results were visually interesting but difficult to use.

The developed algorithm is based on the calculation of elevation around a point. In fact on the dike crest, we are high above the ground on the left and right, so you have a positive altitude difference of both sides. The algorithm is calculated on 4 directions because the dike direction is not known. The width of calculation is parameterized to detect the dikes of that given width. The width adjustment allows detecting larger or smaller structures.

The results (see Figure 3) highlight elevations higher than 1 metre, characterizing the dikes, artificial or natural embankments.

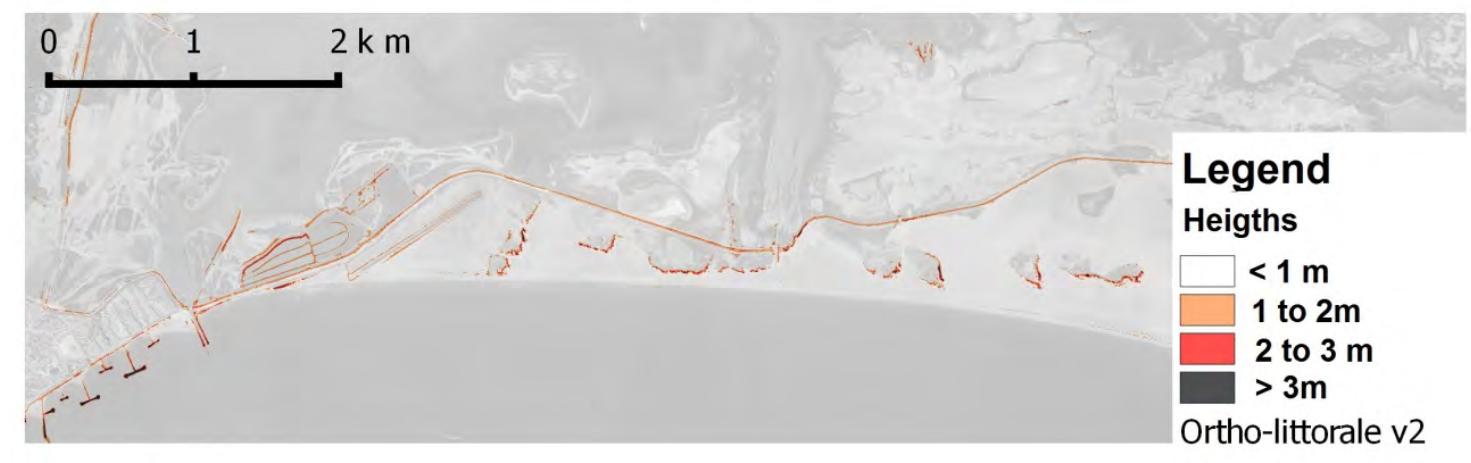

Figure 3. Example of dike detections (sea dike in Camargue).

\section{Conclusions and perspectives}

The submerged areas maps and the potentially protected areas maps produced and the embankments detection allow to better understand the phenomena while studying wide areas that do not allow numerical hydraulic modeling.

As part of the determination of ZERIP (Zones d'Endiguement à Risques Importants Potentiels $=$ Embankment Zones of Important Priority Risk), these methods are being implemented on the French coast, among others, on the Mediterranean coast. They can 
be useful for the identification of sea and river flooding protections, for example for the implementation of the GEMAPI French Law (January 27th 2014).

\section{References}

EP, COUNCIL OF THE EU -The European Parliament, Council of the European Union- (2007). Directive 2007/60/EC of the European Parliament and of the Council of 23 October 2007 on the assessment and management of flood risks. Official Journal of the European Union, pp L 288/27-L 288/34. Available on URL :

http://eur-lex.europa.eu/legal-content/EN/TXT/?uri=CELEX:32007L0060

TRMAL C., PONS F., ALQUIER M. (2015). Notice de DICARTO packagé en $R$, Cerema, Disponible en ligne sur URL :

http://wikhydro.developpement-durable.gouv.fr/index.php/Notice_de_DICARTO_packag\%C3\%A9_avec_R 